\title{
PERHITUNGAN IURAN PENSIUN UNTUK PENSIUN NORMAL BERDASARKAN METODE BENEFITE PRORATE TIPE CONSTANT DOLLAR
}

\author{
SARIFAH AULIA, HAZMIRA YOZZA, MAIYASTRI \\ Jurusan Matematika, \\ Fakultas Matematika dan Ilmu Pengetahuan Alam, Universitas Andalas, \\ Kampus UNAND Limau Manis Padang, Indonesia, \\ email : sarifahaulia1310431003@gmail.com
}

\begin{abstract}
Abstrak. Metode Benefit Prorate tipe Constant Dollar merupakan salah satu metode yang digunakan untuk menghitung dana pensiun. Program pensiun yang digunakan pada metode ini adalah program manfaat pasti, yang ditentukan terlebih dahulu adalah besarnya manfaat pensiun. Setelah itu, baru ditentukan besar iuran yang akan dibayarkan peserta program dana pensiun untuk memenuhi manfaat yang akan diterima setelah memasuki usia pensiun. Secara umum besar manfaat dihitung berdasarkan tiga asumsi, yaitu asumsi gaji tahun terakhir, asumsi rata-rata gaji $n$ tahun terakhir dan asumsi ratarata gaji selama bekerja. Untuk menghitung iuran, metode ini tidak tergantung pada besar gaji, melainkan lama peserta bekerja dan besarnya manfaat. Manfaat pensiun terbesar diperoleh dengan mengambil asumsi gaji tahun terakhir. Iuran pensiun terkecil diperoleh dengan mengambil asumsi rata-rata gaji selama bekerja. Perhitungan program dana pensiun menunjukkan bahwa usia masuk kerja dan usia masuk program pensiun akan mempengaruhi besar manfaat yang akan diperoleh dan besar iuran yang akan dibayarkan. Semakin lama seseorang masuk kerja maka manfaat yang didapat akan semakin kecil. Semakin lama seseorang masuk program pensiun semakin besar iuran yang akan dibayarkan.
\end{abstract}

Kata Kunci: Benefit Prorate, Constant Dollar, Pensiun, Asuransi, Anuitas, Manfaat, Iuran Normal, Mortalita

\section{Pendahuluan}

Setiap orang akan selalu berusaha memenuhi kebutuhan serta menjaga kelangsungan hidup. Tujuan tersebut menjadikan seseorang harus dapat menjaga kesinambungan penghasilannya. Ketika usia produktif, penghasilan didapatkan dengan bekerja. Melewati usia produktif, kesempatan kerja dan mendapatkan penghasilan menjadi terbatas. Untuk mengantisipasi hal tersebut, seseorang perlu membuat rencana kehidupan di masa depan, yaitu dengan memanfaatkan dana pensiun.

Dana pensiun merupakan salah satu bentuk tabungan masyarakat yang mempunyai ciri sebagai tabungan jangka panjang, yang hasilnya dinikmati setelah pegawai memasuki masa pensiun. Penyelenggaraannya dilakukan dalam bentuk program, yaitu program pensiun. Tujuan dari dibentuknya program dana pensiun adalah untuk menyisihkan sebagian dana (iuran) selama masa produktif pegawai, sehingga pada saat berhenti bekerja, dana dan hasil yang diperoleh dari investasi dana tersebut dapat dikembalikan kepada pegawai sebagai ganti gaji yang diper- 
oleh selama bekerja. Manfaat pensiun merupakan sejumlah uang yang diterima oleh peserta program pensiun setelah memasuki masa pensiun.

Secara garis besar program dana pensiun terbagi atas dua program yaitu program pensiun iuran pasti dan program pensiun manfaat pasti. Ada beberapa metode yang dapat digunakan pada perhitungan dana pensiun menggunakan program pensiun manfaat pasti. Metode tersebut antara lain: Accrued Benefit, Cost Prorate, Benefit Prorate dan lainnya. Pada Metode Benefit Prorate besarnya manfaat setiap periode adalah sama. Metode ini terbagi atas dua yaitu Metode Constant Dollar dan Constant Percent of Salary. Perbedaan kedua metode ini adalah dalam penentuan iuran pensiun. Pada Metode Constant Dollar perhitungan iuran pensiun dihitung menggunakan lamanya masa kerja pegawai sedangkan Metode Constant Percent of Salary menggunakan besarnya gaji. Dalam penelitian ini yang digunakan untuk menghitung dana pensiun adalah Metode Benefit Prorate tipe Constant Dollar untuk gender laki-laki.

\section{Landasan Teori}

\subsection{Anuitas}

Anuitas adalah rangkaian pembayaran atau penerimaan tetap dalam jumlah tertentu yang dilakukan secara berkala pada jangka waktu tertentu. Anuitas yang dipakai disini adalah anuitas awal seumur hidup. Nilai tunai dari anuitas seumur hidup sebesar 1 rupiah yang dibayarkan setiap awal periode dan dimulai dari usia $x$ tahun hingga meninggal dengan bunga $i$ per periode dinotasikan dengan $\ddot{a}_{x}$ dan dirumuskan sebagai berikut [2].

$$
\begin{aligned}
\ddot{a}_{x} & =1+v p_{x}+v^{2}{ }_{2} p_{x}+\cdots+v^{w-x}{ }_{(w-x)} p_{x}, \quad t=w-x \\
& =\sum_{t=0}^{w-x} v^{t}{ }_{t} p_{x}
\end{aligned}
$$

\subsection{Fungsi Dasar Aktuaria untuk Asuransi Pensiun}

Fungsi-fungsi yang dapat digunakan adalah sebagai berikut[3]:

(1) Fungsi Kelangsungan Hidup

Fungsi kelangsungan hidup merupakan fungsi yang menunjukkan kemungkinan seseorang masih akif bekerja hingga mencapai usia pensiun yang telah ditentukan. Jika $l_{x}$ merupakan banyaknya pegawai yang masih aktif bekerja pada usia $x$, dan $l_{x+t}$ merupakan banyaknya pegawai yang masih aktif bekerja pada usia $x+t$, maka peluang pegawai yang berusia $x$ tahun masih aktif bekerja hingga mencapai usia $x+t$ yang dilambangkan dengan ${ }_{t} p_{x}$. Maka ${ }_{t} p_{x}$ dapat dinyatakan dengan

$$
{ }_{t} p_{x}=\frac{l_{x+t}}{l_{x}}
$$

(2) Fungsi Tingkat Suku Bunga

Tingkat suku bunga digunakan untuk menentukan pengurangan dari pembayaran yang akan datang yang disebut juga sebagai nilai sekarang (present 
value). Dalam hal ini, bunga yang digunakan adalah bunga majemuk. Jika $i$ adalah tingkat bunga yang diasumsikan untuk tahun ke $t$, dengan $t=$ $1,2, \cdots, n$, nilai sekarang dari satu satuan uang dalam $n$ tahun ditunjukkan dengan

$$
v^{n}=\frac{1}{(1+i)^{n}} \text {. }
$$

(3) Fungsi Gaji

Perhitungan besarnya nilai manfaat pensiun juga berkaitan dengan besarnya gaji yang diterima, sehingga diperlukan perumusan agar dapat menghitung perkiraan gaji dimasa yang akan datang. Jika diasumsikan besarnya tingkat kenaikan gaji dengan $c$ x 100\% pertahun dan besar gaji per tahun yang berusia $x$ tahun adalah $S_{x}$, maka besarnya gaji yang akan diterima seseorang pegawai yang berusia $x$ tahun setelah $t$ tahun ditunjukkan dengan

$$
S_{x+t}=S_{x}(1+c)^{t}
$$

(4) Fungsi Manfaat Pensiun

Berdasarkan asumsi skala gaji terdapat tiga jenis rumus manfaat yang paling umum digunakan dalam program dana pensiun pasti, yaitu:

(a) Fungsi manfaat berdasarkan asumsi gaji tahun terakhir

Besar nilai manfaat yang akan diterima oleh peserta berdasarkan asumsi gaji terakhir yang dinotasikan dengan $B_{r}$ dapat dirumuskan sebagai berikut:

$$
B_{r}=k(r-y) S_{(r-1)} .
$$

(b) Fungsi manfaat berdasarkan asumsi rata-rata gaji selama $n$ tahun terakhir Besar nilai manfaat yang akan diterima oleh peserta berdasarkan asumsi rata-rata gaji selama $n$ tahun terakhir adalah

$$
B_{r}=k(r-y) \frac{1}{n}\left[\sum_{t=r-n}^{r-1}\left(S_{x}(1+c)^{t}\right)\right] .
$$

(c) Fungsi Manfaat Berdasarkan Asumsi Rata-Rata Gaji Selama Bekerja Besar nilai manfaat berdasarkan asumsi rata-rata gaji selama bekerja dapat dirumuskan sebagai berikut:

$$
\begin{aligned}
B_{r} & =k(r-y) \frac{1}{(r-y)}\left[S_{y}+\cdots+S_{x}+S_{(x+1)}+\cdots+S_{(r-1)}\right], \\
& =k\left[S_{y}+\cdots+S_{x}+S_{(x+1)}+\cdots+S_{(r-1)}\right] .
\end{aligned}
$$

dengan $y$ usia seseorang masuk kerja, $x$ usia pegawai masuk program dana pensiun, $r$ usia pegawai memasuki pensiun normal, $c \%$ kenaikan gaji pegawai dalam 1 tahun, $S_{x}$ besar gaji dalam 1 tahun untuk pegawai berusia $x, k$ proporsi gaji yang digunakan untuk menghitung besar manfaat. 


\subsection{Metode Benefit Prorate tipe Constant Dollar}

(1) Present Value of Future Benefit (PVFB) Present value of future benefit (PVFB) adalah nilai sekarang dari manfaat pensiun berkala yang akan diterima peserta program dana pensiun setiap tahun, mulai saat peserta memasuki usia pensiun normal yaitu saat berusia $r$ tahun sampai meninggal. Secara matematis $(P V F B)_{x}$ dirumuskan sebagai berikut [4]:

$$
(P V F B)_{x}=B_{r} v_{(r-x)}^{(r-x)} p_{x} \ddot{a_{r}} .
$$

(2) Normal Cost (NC)

Secara umum Normal Cost $(N C)$ atau iuran pensiun adalah pembayaran yang dilakukan oleh peserta program dana pensiun untuk memenuhi biaya manfaat pensiun $\left(B_{r}\right)$. Persamaan umum iuran pensiun untuk seorang peserta berusia $x$ dapat dihitung menggunakan persamaan [4]:

$$
(N C)_{x}=b_{x r-x} p_{x} v^{r-x} \ddot{a}_{r} .
$$

(3) Present Value of Future Normal Cost (PVFNC)

Present value of future normal cost $(P V F N C)$ adalah nilai sekarang dari iuran normal yang dibayarkan secara berkala oleh peserta program dana pensiun dimulai saat berusia $x$ tahun sampai memasuki usia pensiun berusia $r-1$ tahun, yang dinotasikan dengan $(P V F N C)_{x}$.

Sehingga nilai sekarang iuran normal untuk pegawai yang masuk program pensiun pada $x$ tahun dan memasuki usia pensiun normal pada $r$ tahun dirumuskan sebagai berikut [1]:

$$
(P V F N C)_{x}=\sum_{t=x}^{r-1}(N C)_{t} v_{t-x}^{t-x} p_{x} .
$$

Nilai sekarang iuran normal pensiun $(P V F N C)_{x}$ sama dengan nilai tunai manfaat masa depan $(P V F B)_{x}$ sebagai berikut.

$$
\begin{aligned}
(P V F N C)_{x} & =\sum_{t=x}^{r-1}(N C)_{t} v_{t-x}^{t-x} p_{x} \\
& =\sum_{t=x}^{r-1}\left(b_{t r-t} p_{x} v^{r-t} \ddot{a}_{r}\right) v_{t-x}^{t-x} p_{x} \\
& =\sum_{t=x}^{r-1} b_{t r-x} p_{x} v^{r-x} \ddot{a}_{r} \\
& =B_{r} r-x p_{x} v^{r-x} \ddot{a}_{r} \\
& =(P V F B)_{x} .
\end{aligned}
$$

\section{Pembahasan}

\subsection{Kasus}

Seorang pegawai berjenis kelamin laki-laki mulai bekerja saat berusia $(y=25)$ tahun, mulai terhitung masuk usia pensiun normal $(r=56)$ tahun. Gaji pokok yang 
diterima pegawai tersebut pada tahun kerja pertama adalah sebesar Rp 2.000.000,00 per bulan, dengan kenaikan gaji $(c=2 \%)$ tiap tahunnya, proporsi nilai manfaat pensiun yang diberikan perusahaan kepada peserta auransi dana pensiun tersebut adalah $(k=2,5 \%)$ dan tingkat suku bunga sebesar $(i=10 \%)$. Akan dibandingkan dana pensiun dengan fungsi manfaat berdasarkan asumsi gaji tahun terakhir, ratarata gaji selama $n$ tahun terakhir, dan rata-rata gaji selama bekerja dengan menggunakan metode Benefit Prorate tipe Constant Dollar.

\subsection{Langkah-langkah}

Dari kasus di atas maka dapat diketahui:

(1) Usia peserta laki-laki mulai bekerja dinyatakan dengan $y$ dan $y=25$

(2) Usia pensiun normal dinyatakan dengan $r$ dan $r=56$

(3) Gaji pokok pada tahun pertama kerja dinyatakan dengan $S_{x}$ dan $S_{x}=$ $R p \quad 2.000 .000,00 \times 12=R p \quad 24.000 .000,00$.

(4) Tingkat kenaikan gaji tiap tahunnya dinyatakan dengan $c$ dan $c=2 \%$.

(5) Besar proporsi nilai manfaat pensiun dinyatakan dengan $k$ dan $k=2,5 \%$.

(6) Tingkat suku bunga sebesar $i=10 \%$.

Misalkan $x$ adalah usia pegawai masuk program dana pensiun. Untuk menentukan besarnya dana pensiun bagi pegawai tersebut dengan menggunakan moetode Benefit Prorate tipe Constant Dollar dengan ketiga asumsi gaji dilakukan langkah-langkah sebagai berikut:

(1) Menentukan nilai anuitas.

(2) Menentukan besar gaji yang diperoleh dengan asumsi kenaikan gaji $2 \%$ setiap tahun.

(3) Menentukan besar manfaat pensiun berdasarkan ketiga asumsi gaji.

(4) Menentukan besar nilai sekarang dari manfaat pensiun ( $P V F B$ ).

(5) Menentukan besar iuran yang akan dibayar peserta program pensiun setiap tahun.

\subsection{Penyelesaian}

(1) Perhitungan anuitas hidup.

Perhitungan anuitas untuk peserta program dana pensiun karena pensiun normal adalah dengan menggunakan anuitas seumur hidup, khususnya yang di bahas disini adalah anuitas awal seumur hidup. Anuitas ini digunakan dalam perhitungan dana pensiun untuk menghitung manfaat yang diterima peserta program dana pensiun dimulai saat memasuki masa pensiun normal yaitu usia 56 tahun. 
Nilai tunai anuitas seumur hidup dapat dihitung sebagai berikut:

$$
\begin{aligned}
\ddot{a}_{56} & =\sum_{t=0}^{55}\left(\frac{1}{1+0,1}\right)^{t}{ }_{t} p_{56} \\
& =\left(\frac{1}{1+0,1}\right)^{0}{ }_{0} p_{56}+\left(\frac{1}{1+0,1}\right)^{1}{ }_{1} p_{56}+\cdots+\left(\frac{1}{1+0,1}\right)^{55}{ }_{55} p_{56} \\
& =\left(\frac{1}{1+0,1}\right)^{0} \frac{90011}{90011}+\left(\frac{1}{1+0,1}\right)^{1} \frac{89065}{90011}+\cdots+\left(\frac{1}{1+0,1}\right)^{55} \frac{0}{90011} \\
& =1(1)+0,95238(0,90909)+\cdots+0,95238(0,00000) \\
& =8,97649
\end{aligned}
$$

\begin{tabular}{|c|c|c|c|c|c|c|c|}
\hline$(x)$ & gaji/bulan $(x)$ & & $S_{x}(\mathrm{Rp})$ & $(x)$ & gaji/bulan $(x)$ & & $S_{x}(\mathrm{Rp})$ \\
\hline 25 & Rp 2.000.000,00 & & $24.000 .000,00$ & 41 & Rp 2.745.571,41 & $\mathrm{Rp}$ & $32.946 .856,92$ \\
\hline 26 & Rp $2.040 .000,00$ & $\mathrm{Rp}$ & $24.480 .000,00$ & 42 & Rp $2.800 .482,84$ & $\mathrm{Rp}$ & $33.605 .794,06$ \\
\hline 27 & $\begin{array}{ll}\text { Rp } 2.080 .800 .00\end{array}$ & $\mathrm{Rp}$ & $24.969 .600,00$ & 43 & $\begin{array}{ll}\mathrm{Rp} & 2.856 .492,50\end{array}$ & $\mathrm{Rp}$ & $34.277 .909,94$ \\
\hline 28 & Rp $2.122 .416,00$ & $\mathrm{Rp}$ & $25.468 .992,00$ & 44 & Rp 2.913.622,35 & $\mathrm{Rp}$ & $34.963 .468,14$ \\
\hline 29 & $\begin{array}{ll}\mathrm{Rp} & 2.164 .864,32\end{array}$ & $\mathrm{Rp}$ & $25.978 .371,84$ & 45 & $\begin{array}{ll}\mathrm{Rp} & 2.971 .894,79\end{array}$ & $\mathrm{Rp}$ & $35.662 .737,50$ \\
\hline 30 & $\mathrm{Rp} 2.208 .161,61$ & $\mathrm{Rp}$ & $26.497 .939,28$ & 46 & $\operatorname{Rp} 3.031 .332,69$ & $\mathrm{Rp}$ & $36.375 .992,25$ \\
\hline 31 & $\mathrm{Rp} 2.252 .324,84$ & $\mathrm{Rp}$ & $27.027 .898,06$ & 47 & Rp $3.091 .959,34$ & $\mathrm{Rp}$ & $37.103 .512,10$ \\
\hline 32 & $2.297 .371,34$ & $\mathrm{Rp}$ & $27.568 .456,02$ & 48 & Rp $3.153 .798,53$ & $\mathrm{Rp}$ & $37.845 .582,34$ \\
\hline 33 & $\mathrm{Rp} 2.343 .318,76$ & $\mathrm{Rp}$ & $28.119 .825,14$ & 49 & $\mathrm{Rp} 3.216 .874,50$ & $\mathrm{Rp}$ & $38.602 .493,99$ \\
\hline 34 & Rp $2.390 .185,14$ & $\mathrm{Rp}$ & $28.682 .221,65$ & 50 & Rp $3.281 .211,99$ & $\mathrm{Rp}$ & $39.374 .543,87$ \\
\hline 35 & $2.437 .988,84$ & $\mathrm{Rp}$ & $29.255 .866,08$ & 51 & $\mathrm{Rp} \quad 3.346 .836,23$ & $\mathrm{Rp}$ & $40.162 .034,74$ \\
\hline 36 & Rp $2.486 .748,62$ & $\mathrm{Rp}$ & $29.840 .983,40$ & 52 & Rp $3.413 .772,95$ & $\mathrm{Rp}$ & $40.965 .275,44$ \\
\hline 37 & Rp $2.536 .483,59$ & $\mathrm{Rp}$ & $30.437 .803,07$ & 53 & Rp $3.482 .048,41$ & $\mathrm{Rp}$ & $41.784 .580,95$ \\
\hline 38 & Rp $2.587 .213,26$ & $\mathrm{Rp}$ & $31.046 .559,13$ & 54 & $\mathrm{Rp} 3.551 .689,38$ & $\mathrm{Rp}$ & $42.620 .272,57$ \\
\hline 39 & Rp 2.638.957,53 & $\mathrm{Rp}$ & $31.667 .490,31$ & 55 & Rp $3.622 .723,17$ & $\mathrm{Rp}$ & $43.472 .678,02$ \\
\hline 40 & Rp 2.691.736,68 & $\mathrm{Rp}$ & $32.300 .840,12$ & & & & \\
\hline
\end{tabular}

(2) Perhitungan besar gaji tiap tahun.

Tabel berikut menunjukkan asumsi besarnya gaji peserta laki-laki $(x)$ tahun dengan kenaikan gaji $2 \%$ per tahun.

Tabel 1. Asumsi besar gaji peserta laki-laki $(x)$ dalam setahun

(3) Perhitungan besar manfaat pensiun, besarnya nilai sekarang dari manfaat pensiun $(P V F B)$ dan iuran pensiun normal $(N C)$.

(a) Asumsi gaji tahun terakhir.

(i) Besar manfaat pensiun.

$$
\begin{aligned}
B_{r} & =k(r-y) S_{r-1} \\
B_{56} & =(2,5 \%)(56-25)(R p \quad 43.472 .678,02) \\
& =R p \quad 33.691 .325,46
\end{aligned}
$$

(ii) Nilai sekarang dari manfaat pensiun $\left(P V F B_{x}\right)$ 
- Usia masuk program pensiun $(x=25)$ tahun.

$$
\begin{aligned}
(P V F B)_{25} & =B_{56} 56-25 p_{25} v^{56-25} \ddot{a}_{56} \\
& =B_{56} \frac{l_{56}}{l_{31}} v^{31} \ddot{a}_{56} \\
& =R p \quad 33.691 .325,46 \frac{90011}{98177}(0,05210)(8,97649) \\
& =R p \quad 14.445 .654,98
\end{aligned}
$$

- Usia masuk program pensiun $(x=26)$ tahun.

$$
\begin{aligned}
(P V F B)_{26} & =B_{56} \quad 56-26 p_{26} v^{56-26} \ddot{a}_{56} \\
& =B_{56} \frac{l_{56}}{l_{30}} v^{30} \ddot{a}_{56} \\
& =R p \quad 33.691 .325,46 \frac{90011}{98094}(0,05731)(8,97649) \\
& =R p \quad 15.903 .665,63
\end{aligned}
$$

(iii) Besar iuran pensiun yang akan dibayar setiap tahun.

- Usia masuk program pensiun $(x=25)$ tahun.

$$
\begin{aligned}
(N C)_{25} & =\frac{B_{56}}{56-25}{ }_{56-25} p_{25} v^{56-25} \ddot{a}_{56} \\
& =\frac{B_{56}}{31} \frac{l_{56}}{l_{31}} v^{31} \ddot{a}_{56} \\
& =\frac{R p}{33.691 .325,46} \\
& =R p \quad \frac{90011}{98177}(0,05210)(8,97649)
\end{aligned}
$$

- Usia masuk program pensiun $(x=26)$ tahun.

$$
\begin{aligned}
(N C)_{26} & =\frac{B_{56}}{56-25}{ }_{56-26} p_{26} v^{56-26} \ddot{a}_{56} \\
& =\frac{B_{56}}{31} \frac{l_{56}}{l_{30}} v^{30} \ddot{a}_{56} \\
& =\frac{R p}{33.691 .325,46} \frac{31}{980011}(0,05731)(8,97649) \\
& =R p \quad 513.021,47
\end{aligned}
$$

(b) Asumsi rata-rata gaji $n$ tahun terakhir, misalkan $n=10$.

(i) Besar manfaat pensiun

$$
\begin{aligned}
B_{r} & =k(r-y) \frac{1}{n}\left[\sum_{t=r-n}^{r-1}\left(S_{x}(1+c)^{t}\right)\right] \\
B_{56} & =(2,5 \%)(56-25) \frac{1}{10}\left[\sum_{t=46}^{55}\left(S_{x}(1+c)^{t}\right)\right] \\
& =(0,065)(R p \quad 35.662 .737,50+\cdots+R p \quad 43.472 .678,02) \\
& =R p \quad 30.868 .789,89
\end{aligned}
$$


(ii) Nilai sekarang dari manfaat pensiun

- Usia masuk program pensiun $(x=25)$ tahun.

$$
\begin{aligned}
(P V F B)_{25} & =B_{56} \quad 56-25 p_{25} v^{56-25} \ddot{a}_{56} \\
& =B_{56} \frac{l_{56}}{l_{31}} v^{31} \ddot{a}_{56} \\
& =R p \quad 30.868 .789,89 \frac{90011}{98177}(0,05210)(8,97649) \\
& =R p \quad 13.235 .451,03
\end{aligned}
$$

- Usia masuk program pensiun $(x=26)$ tahun.

$$
\begin{aligned}
(P V F B)_{26} & =B_{56} \quad 56-26 p_{26} v^{56-26} \ddot{a}_{56} \\
& =B_{56} \frac{l_{56}}{l_{30}} v^{30} \ddot{a}_{56} \\
& =R p \quad 30.868 .789,89 \frac{90011}{98094}(0,05731)(8,97649) \\
& =R p \quad 14.571 .314,90
\end{aligned}
$$

(iii) Besar iuran pensiun yang akan dibayar setiap tahun

- Usia masuk program pensiun $(x=25)$ tahun.

$$
\begin{aligned}
(N C)_{25} & =\frac{B_{56}}{56-25} 56-25 p_{25} v^{56-25} \ddot{a}_{56} \\
& =\frac{B_{56}}{31} \frac{l_{56}}{l_{31}} v^{31} \ddot{a}_{56} \\
& =\frac{R p \quad 30.868 .789,89}{31} \frac{90011}{98177}(0,05210)(8,97649) \\
& =R p \quad 426.950,03
\end{aligned}
$$

- Usia masuk program pensiun $(x=26)$ tahun.

$$
\begin{aligned}
(N C)_{26} & =\frac{B_{56}}{56-25} 56-26 p_{26} v^{56-26} \ddot{a}_{56} \\
& =\frac{B_{56}}{31} \frac{l_{56}}{l_{30}} v^{30} \ddot{a}_{56} \\
& =\frac{R p \quad 30.868 .789,89}{31} \frac{90011}{98094}(0,05731)(8,97649) \\
& =R p \quad 470.042,42
\end{aligned}
$$

(c) Asumsi rata-rata gaji selama bekerja.

(i) Besar manfaat pensiun.

$$
\begin{aligned}
& B_{r}=k\left[S_{y}+\cdots+S_{x}+S_{(x+1)}+\cdots+S_{(r-1)}\right]
\end{aligned}
$$

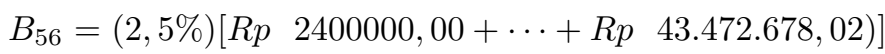

$$
\begin{aligned}
& =\operatorname{Rp} \quad 25.427 .664,47
\end{aligned}
$$

(ii) Nilai sekarang dari manfaat pensiun 
- Usia masuk program pensiun $(x=25)$ tahun.

$$
\begin{aligned}
(P V F B)_{25} & =B_{56} 56-25 p_{25} v^{56-25} \ddot{a}_{56} \\
& =B_{56} \frac{l_{56}}{l_{31}} v^{31} \ddot{a}_{56} \\
& =R p \quad 25.427 .664,47 \frac{90011}{98177}(0,05210)(8,97649) \\
& =R p \quad 10.902 .487,89
\end{aligned}
$$

- Usia masuk program pensiun $(x=26)$ tahun.

$$
\begin{aligned}
(P V F B)_{26} & =B_{56} 56-26 p_{26} v^{56-26} \ddot{a}_{56} \\
& =B_{56} \frac{l_{56}}{l_{30}} v^{30} \ddot{a}_{56} \\
& =R p \quad 25.427 .664,47 \frac{90011}{98094}(0,05731)(8,97649) \\
& =R p \quad 12.002 .884,06
\end{aligned}
$$

(iii) Besar iuran pensiun yang akan dibayar setiap tahun

- Usia masuk program pensiun $(x=25)$ tahun.

$$
\begin{aligned}
(N C)_{25} & =\frac{B_{56}}{56-25}{ }_{56-25} p_{25} v^{56-25} \ddot{a}_{56} \\
& =\frac{B_{56}}{31} \frac{l_{56}}{l_{31}} v^{31} \ddot{a}_{56} \\
& =\frac{R p}{25.427 .664,47} \frac{31}{98177}(0,05210)(8,97649) \\
& =R p \quad 351.693,16
\end{aligned}
$$

- Usia masuk program pensiun $(x=26)$ tahun.

$$
\begin{aligned}
(N C)_{26} & =\frac{B_{56}}{56-25}{ }_{56-26} p_{26} v^{56-26} \ddot{a}_{56} \\
& =\frac{B_{56}}{31} \frac{l_{56}}{l_{30}} v^{30} \ddot{a}_{56} \\
& =\frac{R p}{25.427 .664,47} \frac{31}{98094}(0,05731)(8,97649) \\
& =R p \quad 387.189,81
\end{aligned}
$$

Pada Tabel 2 dan Tabel 3 dilakukan perbandingan besar iuran pensiun berdasarkan manfaat ketiga asumsi gaji, yang masuk kerja pada usia $y$ dan masuk program dana pensiun pada usia $x$.

Berdasarkan Tabel (2) dan Tabel (3), diperoleh bahwa:

(1) Asumsi besar manfaat pensiun sangat beRp engaruh terhadap besarnya iuran pensiun dan nilai sekarang dari manfaat pensiun. Berikut adalah perbandingan besar manfaat pensiun secara berturut-turut dari yang terkecil: berdasarkan asumsi rata-rata gaji selama bekerja, asumsi rata-rata gaji selama $n$ tahun terakhir, asumsi gaji tahun terakhir.

(2) Usia pada saat mengikuti program pensiun juga mempengaruhi besarnya iuran pensiun dan nilai sekarang dari manfaat pensiun. 
Tabel 2. Perbandingan besar nilai sekarang dari manfaat pensiun menggunakan asumsi gaji tahun terakhir, asumsi rata-rata gaji $n$ tahun terakhir dan asumsi rata-rata gaji selama bekerja.

\begin{tabular}{|c|c|c|c|}
\hline $\mathrm{x}$ & gaji tahun terakhir & rata-rata gaji $n$ terakhir & rata-rata gaji selama bekerja \\
\hline 25 & Rp 14.445.654,98 & $\mathrm{Rp} 13.235 .451,03$ & $\operatorname{Rp} 10.902 .487,89$ \\
\hline 26 & Rp 15.903.665,63 & Rp 14.571.314,90 & Rp 12.002.884,06 \\
\hline 27 & $\mathrm{Rp} 17.508 .668,26$ & $\mathrm{Rp} 16.041 .856,30$ & $\mathrm{Rp} 13.214 .218,67$ \\
\hline 28 & Rp 19.274.677,62 & Rp 17.659.915,88 & Rp 14.547.068,97 \\
\hline 29 & Rp 21.217.961,09 & Rp 19.440.398,20 & Rp 16.013.712,37 \\
\hline 30 & $\mathrm{Rp} 23.357 .180,45$ & $\mathrm{Rp} 21.400 .401,61$ & $\mathrm{Rp} 17.628 .233,36$ \\
\hline 31 & Rp 25.712.355,84 & Rp 23.558.269,05 & Rp 19.405.741,63 \\
\hline 32 & Rp 28.306.186,55 & Rp 25.934.798,15 & Rp 21.363.368,88 \\
\hline 33 & Rp 31.162.657,85 & Rp 28.551.964,77 & Rp 23.519.217,40 \\
\hline 34 & Rp 34.307.760,78 & Rp 31.433.582,52 & Rp 25.892.903,23 \\
\hline
\end{tabular}

Tabel 3. Perbandingan besar iuran pensiun menggunakan asumsi gaji tahun terakhir, asumsi ratarata gaji $n$ tahun terakhir dan asumsi rata-rata gaji selama bekerja.

\begin{tabular}{|c|c|c|c|}
\hline $\mathrm{x}$ & gaji tahun terakhir & rata-rata gaji $n$ terakhir & rata-rata gaji selama bekerja \\
\hline 25 & $\mathrm{Rp} 465.988,87$ & Rp $426.950,03$ & Rp 351.693,16 \\
\hline 26 & Rp 513.021,47 & $\mathrm{Rp} 470.042,42$ & Rp 387.189,81 \\
\hline 27 & Rp 564.795,75 & Rp $517.479,24$ & Rp $426.265,12$ \\
\hline 28 & Rp 621.763,79 & Rp 569.674,71 & Rp 469.260,29 \\
\hline 29 & Rp 684.450,36 & Rp 627.109,62 & Rp 516.571,37 \\
\hline 30 & $\mathrm{Rp} 753.457,43$ & Rp 690.335,54 & Rp 568.652,69 \\
\hline 31 & Rp 829.430,83 & Rp 759.944,16 & $\operatorname{Rp} 625.991,67$ \\
\hline 32 & Rp 913.102,79 & Rp 836.606,39 & Rp 689.140,93 \\
\hline 33 & Rp 1.005.247,03 & Rp 921.031,12 & Rp 758.684,43 \\
\hline 34 & Rp 1.106.701,96 & Rp 1.013.986,53 & Rp 835.254,94 \\
\hline
\end{tabular}

(a) Secara berturut-turut besarnya nilai sekarang manfaat pensiun dari usia yang terkecil: $(P V F B)_{25},(P V F B)_{26},(P V F B)_{27}, \cdots$

(b) Secara berturut-turut besarnya iuran pensiun dari usia yang terkecil: $(N C)_{25},(N C)_{26},(N C)_{27}, \cdots$. Hal ini berlaku untuk ketiga asumsi manfaat pensiun.

\section{Kesimpulan}

(1) Asumsi manfaat pensiun akan mempengaruhi besarnya iuran pensiun yang akan dibayarkkan oleh peserta program pensiun. secara berturut-turut dari asumsi yang terkecil: manfaat pensiun dengan asumsi rata-rata gaji selama bekerja, manfaat pensiun dengan asumsi rata-rata gaji $n$ tahun terakhir, manfaat pensiun dengan asumsi gaji tahun terakhir.

(2) Besar iuran pensiun normal yang akan dibayarkan setiap tahunnya secara berturut-turut dari yang terkecil: $(N C)_{y},(N C)_{y+1}, \cdots,(N C)_{r-1}$. Hal ini berlaku untuk ketiga asumsi manfaat pensiun. 


\section{Daftar Pustaka}

[1] Bowers, N.L. 1997. Actuarial Mathematics. Schaumburg (DE): The Society of Actuaries.

[2] Futami, T. 1993. Matematika Asuransi Jiwa Bagian I. Herliyanto, Gatot (Penerjemah). Tokyo: Oriental Life Insurance Cultural Development Center. Terjemahan dari : Seimei Hoken Sugaku, Jokan .

[3] Larson, R.E., E.A. Gaumnitz.1962. Life Insurance Mahematics. John Wiley dan Sons, Inc. New York.

[4] Winklevoss, H.E. 1993. Pension Mathematics with Numerical Illustrations, $2^{\text {nd }}$ edition. Pension Research Council, USA. 